\title{
Reflections on Architecture Design Education III. A Model of Design Process-Systems Approach
}

\author{
By Fathi Bashier*
}

\begin{abstract}
Recognizing the failure of traditional design and the need for a new approach a research study is now being conducted in the master studio at Wollega University, Ethiopia. The research project aims to explore knowledge mechanism within the design process-system and to develop a 'theory of design knowledge' based on the integration of rationality and creativity. The study is documented in a series of articles entitled "Reflections on architecture design education". Article (I) introduced 'the integrated design paradigm' as a theoretical knowledge base, which laid the foundations for the theory of design knowledge. Article (II) developed an improved version of the theory of design knowledge based on systems theory, and proposed the 'design process-systems'. In this article (III) the research project is presented. A more developed model of the design process-system which is currently being developed in the studio is introduced. The model acts as a research plan where the proposed theory of design knowledge is suggested as a working hypothesis, will be developed and tested. The last section of this article is devoted to an empirical study, which deals with the first part of students' research work of defining the design problem, identifying problem solving and articulating design proposal. A complete documentation of the research findings will only be possible when the study is fully accomplished in a future article. The research method is based on the observation and analysis of the research findings.
\end{abstract}

\section{Introduction}

Studies have recognized the failure of the traditional design approach both in practice and in the studio. They showed that design problems today are too complex for the traditional approach to cope with. ${ }^{1}$ They criticized the traditional approach for lacking objective knowledge ${ }^{2}$ and expressed a new interest in a better quality design. ${ }^{3}$ In the mid-1970s and the early 1980s, there has been a significant shift in focus within the field of design research towards the aim of creating a 'design discipline'. ${ }^{4}$ The problem is that any attempt to define design as a discipline is unlikely to achieve objectives because of the lack of integrated design theory. Although design is usually a result of

\footnotetext{
* Professor, Wollega University, Ethiopia.

1. Nigel Cross, "Designerly ways of knowing: Design discipline versus design science," Design Issues 17, no. 3 (2001): 49-55.

2. Ivar Holm, Ideas and Beliefs in Architecture and Industrial Design (Doctoral thesis. Oslo School of Architecture and Design, 2006).

3. Charles Owen, "Design research: building the knowledge base," in Design Studies 19, no. 1 (1998): 9- 20.

4. Nigel Cross, From a design science to a design discipline: Understanding designerly ways of knowing and thinking (2007).
} 
integrated thinking, described as systems approach integrated response, ${ }^{5}$ there is no design theory that exists at the moment that can describe the design process in a coherent way. In the absence of such a theory that shows how the rational and the creative knowledge of the design problem integrate, it is difficult to describe the process within a discipline-based framework.

It has been suggested that the attempts to define design as a discipline have since the 1980s given rise to design thinking, the process, as the focus of research. ${ }^{6}$ Owen $(2006)^{7}$ has drawn attention to the potential of design thinking as a complement to science thinking. Earlier in 2002 the complementary nature of research and design was revealed by Grout and Wang (2002). ${ }^{8}$ Design thinking, rather than focusing on the end product, for better quality design services is the ultimate goal of this study. The study proposes to achieve its goal by proper understanding the knowledge mechanism within design process-systems based on new conceptualization of the complementary relationship of rational and creative design approaches. For this task the study proposes the 'theory of design knowledge'. It aims to explore knowledge mechanism within design process-systems and to explain how the rational and the creative approaches operate to integrate knowledge. To this end the study introduced the integrated design paradigm. ${ }^{9}$

In this study, the integrated design paradigm acts as a framework for an empirical study currently being conducted in the design research master studio at Wollega University, Ethiopia. The aim of the research project is to explore the design process and to develop a new 'theory of design knowledge' based on the integrated design paradigm. The study is documented in a series of articles entitled "Reflections on architecture design education" by the author, of which the first two articles (I, II) are already published. Article (I) introduced 'the integrated design paradigm' as a theoretical knowledge base of design thinking, which laid the foundations for the development of the theory of design knowledge. ${ }^{10}$ Article (II), the second in the series, developed an improved version of the theory of design knowledge based on the systems theory, in the light of which the initial concept of the 'design process-systems' was proposed. ${ }^{11}$ In article (III) the research project was presented. A model of the design process-system, which has been developed in the studio, was introduced as a research plan where the proposed theory of design knowledge

5. Bryan Lawson, How designers think: The design process demystified (UK: Elsevier, 2005); Nigel Cross, Design thinking (London: Bloomsbury Publishing Plc, 2011).

6. Cross, From a design science to a design discipline: Understanding designerly ways of knowing and thinking.

7. Charles Owen, Design thinking: Driving innovation (USA: Institute of Design, Illinois Institute of Technology, 2006).

8. Linda Grout and David Wang, Architectural Research Methods (New York: John Wiley \& Sons Inc., 2002).

9. Fathi Bashier, "Reflections on architecture design education (II): The integrated design paradigm," in International Journal of Science and Technology (STECH) 5, no. 1 (2016): 1-13.

10. Bashier, "Reflections on architecture design education: The return of rationalism in the studio," in Frontiers of Architectural Research. Elsevier (2014).

11. Bashier, "Reflections on architecture design education (II): The integrated design paradigm." 
was suggested as a working hypothesis. The model is simultaneously being used by students as a methodology of design research in their studio projects, experimented on and is gradually improved.

In the present article (IV) an empirical study of the students' design research is presented, discussed and analyzed. Through empirical investigation in students' research work, the theory of design knowledge is verified.

\section{The Study Problem and Goals}

Theorists have since the early days of the design methods movement recognized the dual nature of design and the need to balance creativity and rationality within the design process. Jones $(1992)^{12}$ argued that rationality and creativity should co-exist instead of one excluding the other. Since the 1950s, writers have recognized these concepts as mutually interdependent and should not consider them as separate. ${ }^{13}$ It has been noted that innovation requires both creativity and rationality, Owens (2006) argues that "A combination of science thinking and design thinking is better than either alone as a source of advice". ${ }^{14}$

Although the dual nature of design has long been appreciated, there is no theory yet developed that could describe design in a coherent way. None of the two available theories, the rational problem-solving paradigm introduced by Simon $(1969)^{15}$ and the reflective practice paradigm proposed by Schon (1983), ${ }^{16}$ could describe how the rational and the creative knowledge within the design process integrate. It has been suggested that these theories deal with different aspects of design. Their ability to describe the integration of the rational and creative aspects of the process is doubtful. ${ }^{17}$

It is obvious that lacking balance is the dominant feature of style architecture today. It is often suggested in the literature that there is a conceived gap between the rational and the creative aspects of contemporary design. In good architecture, there should be no gap between rational and creative thinking. Lawson (2005) pointed out that "good design is usually an integrated response to a whole range of issues" including rationality and aesthetics. He argued that the best way to identify good designers "is the ability 1992).

12. John Chris Jones, Design Methods, $2^{\text {nd }}$ edition (New York: John Wiley \& Sons Inc.,

13. Peter Kroes, Creativity and rationality in design: enemies or brothers in arms? CEPHAD 2010, plenary session, the borderland between philosophy and design research (Copenhagen: DK- 2100 Copenhagen, 2010); Hernan Casakin, Factors of design problemsolving and their contribution to creativity (2008); Phillip C. Wankat and Frank S. Oreovicz, Teaching engineering (School of Chemical Engineering, Purdue University, 1993).

14. Owen, Design thinking: Driving innovation.

15. Hurbert Simon, The science of the artificial (Cambridge, MA: MIT Press, 1969).

16. Donald A. Schon, The reflective practitioner: How professionals think in action (USA: Basic Books Inc., 1983).

17. Kees Dorst, The Design Methodology Group (Faculty of Industrial Design Engineering. TU Delft, 1995); Dorst, "The problem of design problems," in Expertise in design, Design Thinking Research Symposium 6 (ed.) E. Edmonds and N. G. Cross (Australia: Creativity and Cognition Studies Press, 2003), 17-19. 
to integrate and combine". ${ }^{18}$ The question is how the knowledge mechanism within the design process-system operates through the rational and the creative design channels and how knowledge is integrated? Addressing this question is going to be the core focus in this study.

Understanding the knowledge mechanism and the role of each of the rational and the creative approaches within design process-systems constitutes the research topic in the ongoing empirical study in the master studio at Wollega University. As an entry point the study introduced the integrated design paradigm ${ }^{19}$ as a theoretical base of the process-system and a framework of design research. The research project has two aims: (a) to explore the knowledge mechanism throughout the implementation of the different stages of the research plan; and (b) to develop a 'theory of design knowledge', which describes how the knowledge mechanism operates and performs the task of knowledge integration. In this study the theory of design knowledge is working hypothesis based on the design principles, which the integrated design paradigm stands for. Parallel with the research project, students are doing their own research work in studio projects. The interface between the research project presented in this article and students' research work is the investigation in the research project, which takes empirical data from students' research.

A model of the design process-system has been developed in the studio. It has double functions. It is developed as a research plan framed by the integrated design paradigm, in which the proposed theory of design knowledge is developed and empirically tested. The model at the same time is being used by students as a methodology of research design, experimented on and gradually improved.

The present article (III) has two aims: firstly, to introduce the research project and to document the development of the design process-system's model in the studio; secondly, to articulate the 'theory of design knowledge' as the research hypothesis. In the last section of the present article an empirical study of students' research is presented, discussed and analyzed. It deals with the first part of the students' research work concerned with defining the design problem, identifying problem solving approach and articulating the design proposal. Through the empirical investigation in students' research work presented in this article and the following ones, the theory of design knowledge is verified. The research method is based on reporting evidence that comes from observation, analysis and articulation of the design research experiment in the studio.

\section{Literature Review}

Cross $(2011)^{20}$ showed that 'there is a 'systems approach' adopted by innovative designers. This study takes Cross' argument a little further and regards the design process from the perspective of the general systems theory

18. Lawson, How designers think: The design process demystified.

19. Bashier, "Reflections on architecture design education (II): The integrated design paradigm."

20. Cross, Design thinking. 
as a system of knowledge in interaction within the wider knowledge environment. The general systems theory was originally proposed by biologist Von Bertalanffy (1928). ${ }^{21}$ He postulates a new discipline called the General System Theory. Von Bertalanffy proposed that a system could be broken down into its individual components and that a system is characterized by the interactions of its components and the nonlinearity of those interactions. Systems theory provides an internally consistent framework for classifying and evaluating the world. ${ }^{22}$

The subject matter General System Theory is the formulation and derivation of those principles which are valid for 'systems' in general. Thus, a basic problem posed to modern science is a general theory of organization. General system theory is, in principle, capable of giving exact definitions for such concepts and, in suitable cases, of putting them to quantitative analysis.

While in the past, science tried to explain observable phenomena by reducing them to an interplay of elementary units investigable independently of each other, conceptions appear in contemporary science that are concerned with what is somewhat vaguely termed as 'wholeness', i.e. problems of organization, phenomena not resolvable into local events, dynamic interactions manifest in difference of behavior of parts when isolated or in a higher configuration, etc.; in short, 'systems' of various order not understandable by investigation of their respective parts in isolation. General System Theory, therefore, is a general science of 'wholeness'. There is a general tendency towards integration in the various sciences, natural and social. Such integration seems to be centered in a general theory of systems. ${ }^{23}$

The influence of systems theory on establishing the foundation of systematic design since the early days of the 'design methods movement' has been recognized. ${ }^{24}$ In a more recent study- how designers think and workCross $(2011)^{25}$ finds that innovative designers adopt a broad 'systems approach' to the problem. An approach which he says appears to be common across all his case studies. He quotes Maccoby who suggested that innovators have systems mind, one that sees things in terms of how they relate to each other in producing results. Maccoby, according to Cross, describes that systems are considered in terms of all the parts working together. This concept is valid when applied to the design process. In this study, the design process as a system of knowledge is considered holistically where all knowledge components interact to produce new knowledge.

System theory helps understanding the design process as a system of knowledge with emphasis on the interaction of knowledge within the system and between the system and the wider knowledge environment. The study uses systems theory to explore knowledge processing and to explain the mechanism

21. Ludwig Von Bertalanffy, General system theory (1928).

22. David S. Walonick, General systems theory (1993).

23. Von Bertalanffy, General system theory.

24. Nigan Bayazit, "Investigating design: a review of forty years of design research," Design Issues 20, no. 1. Massachusetts Institute of Technology (2004).

25. Cross, "Designerly ways of knowing: Design discipline versus design science." 
of knowledge interaction within the organizational framework of design knowledge conception.

Walonick (1993) identifies three general approaches for evaluating subsystems. A holist approach is to examine the system as a complete functioning unit. A reductionist approach looks downward and examines the subsystems within the system. The functionalist approach looks upward from the system to examine the role it plays in the larger system. All three approaches recognize the existence of subsystems operating within a larger system. $^{26}$ The study finds that a combination of all three methods together should constitute a useful approach for studying the design process system. Design process systems should be studied in a holistic manner, which is characterized by considering the interaction of knowledge within the different components as well as across the system and the wider knowledge environment in a nonlinear interactive and constantly progressing movement.

System thought has been influential in architecture theory in the recent years. The design process, as seen from the perspective of the integrated design paradigm, is an open system within the broader knowledge environment. Walonick $(1993)^{27}$ calls this a bilateral relationship that exists between the environment and the components of different systems operating within the environment. The design process system can be considered a controlled open system. Based on Walonick, the basic characteristics of the design process as an open system is the dynamic interaction of its components with the environment. It receives input knowledge from the environment and releases output knowledge to the environment.

The communication of knowledge between the design process system and the environment can be conceived as a permanent evolutionary pattern in which as Schon $(1983)^{28}$ describes "Researchers are supposed to provide the basic and applied science from which to derive techniques for diagnosing and solving the problems of practice. Practitioners are supposed to furnish researchers with problems for study and with tests of the utility of research results". Owens $(2005)^{29}$ divides creative people in two groups, the finders and the makers. In a similar way the architect is a finder and inventor, whose design work is a combination of discovery and invention. Architects play two roles in making designs: producing knowledge (discovery) and using knowledge (invention). The role of the architect in practice can be conceived in his dual capacity as a researcher and a designer.

Markus (1972) ${ }^{30}$ presented useful systems models describing their content and how they work. Based on Markus the study describes knowledge structure within the design process systems. The study regards the design process a

26. Walonick, General systems theory.

27. Ibid.

28. Schon, The reflective practitioner: How professionals think in action.

29. Owens, "Design thinking. What it is. Why it is different. Where it has new value," The International Conference on Design Research and Foundation for the Future October 18November 1, 2005 (USA: Institute of Design, Illinois Institute of Technology, 2005).

30. Thomas A. Markus, "A doughnut model of the environment and its design," in Design Participation (London: Academy Editions, 1972). 
system of knowledge in which the interaction of the different types of component knowledge within and across the process system and the environment take place through knowledge producing and using channels, rational and creative methods, of the design process. The study distinguishes between objectives and goals to reach objectives. It is obvious that need represents the primary objective of the design process, whereas the specific physical environments required for the need to be fulfilled can be classified as goals. The design process achieves its objective by a number of goals, which are represented in the form of design knowledge, they are: (1) activities: design objectives generate activities; (2) the (physical) environment: activities must have space in order to function properly. Space design or planning is ordered by the basic principles of design; (3) design context: this is mainly the technical knowledge used in the construction of buildings in addition to a host of social, environmental, economic etc. values which are manifest in the design criteria and constraints.

Jaskiewicz (2007) draws an interesting analogy between what he describes as complex systems and living organisms. A lot can be learned from nature, he suggests. The most important characteristic of their similarity is that the design process similar to the living organisms doesn't end when the design is complete or a building is materialized. What is relevant to this study is the notion that buildings keep interacting with the environment after construction, as they are continuously being studied by other designers and commented upon by critics. As Jaskiewicz noted "Even though an architect may not be involved in them anymore, buildings keep on mutating and re-adapting to their environment...". ${ }^{31}$ This kind of thinking may open the way for design processsystems to develop with built-in self-regulating capacity like in natural organisms, which transcends the occasional design object to the permanent production of knowledge.

The insight drawn from the literature has lead to an improved understanding of the design process as a complex system of knowledge. Bertalanffy (1928) showed that the interaction of a system's components rather than the behavior of the individual ones that characterizes the complexity of systems (Bertalanffy, 1928). ${ }^{32}$ Design has been described as systems approach integrated response (Cross, 2011; Lawson, 2005). The study is an attempt to take this definition a step further and to explore knowledge mechanism within design process systems. Based on system theory, the study suggests that the design process can be viewed as a knowledge-based system in constant interaction with environment, which exchanges knowledge within and across the boundaries of the system involving receiving, producing and communicating new knowledge back to the environment.

Understanding the knowledge mechanism within design process-systems can open the way for architects to get involved in their strategic capacity in a

31. Tomasz Jaskiewicz, "Process-driven architecture: Design techniques and methods," $3 r d$ Int"l IASCAAD Conference on embodying virtual architecture (Alexandria, Egypt: ASCAAD07, 2007).

32. Von Bertalanffy, General system theory. 
new role, which transcends the conventional one focused on the end product to a much wider role across the whole of the design process.

\section{The Integrated Design Paradigm}

The term paradigm in common usage is an exemplar or a model. However, the term has come to mean something more specific in the recent time. The study follows Coolican to illustrate the use of the term paradigm in this research. According to Coolican (2004) "A paradigm is a theoretical framework" it was defined as "a loose collection of logically related assumptions, concepts and propositions that orient thinking and research". Another definition described paradigm as a way of seeing the world that frames a research topic and influences the way that we think about the topic. ${ }^{33}$ These definitions provided important guidance, as the following discussion shows, for the establishment of the integrated design paradigm in terms of its meaning, structure and functions.

The integrated design paradigm is based on knowledge from the literature, analytical observation in the studio and logical argumentation. The philosophy, underlying the integrated design paradigm emerges from two closely interrelated concepts: the first is the nature of the design process as a system of knowledge in which blending the rational and the creative knowledge is in the center of its activity as systems theory explains. Von Bertalanffy, (1928) showed that understanding a system is dependent on knowing the integration of its components. He explained that systems of various orders are not understandable by investigation of their respective parts in isolation. There is a general tendency towards integration which is centered to a general theory of systems. ${ }^{34}$ The design process is seen from the perspective of the integrated design paradigm as a system within which design knowledge is exchanged through interaction with the wider knowledge environment. This mechanism is expected to be further explored through the empirical investigation in students' research work.

The other concept underlying the philosophy of the integrated design paradigm is knowledge evolution. The integrated design paradigm takes an evolutionary view of the world. Evolution is the method of incremental improvement. In real life practice new ideas often stem from older solutions by gradual improvement. In architecture, there are many instances in which brilliant new ideas were developed from old ones by constant improvement and refinement over a long period of time.

The integrated design paradigm can be seen as an overall integrating context, which focuses on the relationship between the integration of the rational and the creative knowledge of design problems on the one hand and learning from past experience on the other. Studies showed that the rational

33. Hugh Coolican, Research Methods and Statistics in Psychology, $4^{\text {th }}$ edition (London: Hodder Arnold, 2004).

34. Von Bertalanffy, General system theory. 
and the creative design knowledge are conceptually different, ${ }^{35}$ in terms of their objective and subjective nature. Creative knowledge is generally regarded as subjective and therefore considered indeterminate, the case which poses a problem in the design process. The integrated design paradigm suggests that the creative knowledge can be considered determinate to some extent. It proposes to bridge the gap between objective and subjective knowledge by finding and widening the determinate area in creative knowledge.

\section{The Theory of Design Knowledge as a Working Hypothesis}

Several studies showed different types of design knowledge and the different ways of knowledge acquisition. ${ }^{36}$ This study finds that the development of design knowledge requires, in addition to understanding the different types of knowledge and the different ways of knowing, that the knowledge development mechanism within the design process-systems should receive more attention. The proposed theory of design knowledge is intended to address this question. It aims to describe the design knowledge mechanism and how it operates to blend the rational and the creative knowledge.

The theory of design knowledge suggests that blending the rational and the creative knowledge of design problems is dependent on the evolution of knowledge from the study of the precedents. Observation in the development of architecture design throughout history indicates that the case of a balanced integration in architecture is often associated with design evolution from the experiences of the past. Designs that develop from old ideas are usually identified with a balanced integration of the rational and the creative aspects of design.

Similar views were expressed by Grout and Wang (2002). ${ }^{37}$ They noted that research has been an integral part of design throughout architecture history. This statement implies that good architecture throughout history, which usually shows a remarkable balance of rationality and creativity, has been a result of evolution by learning from the experiences of the past. Unlike the contemporary stylist architecture, which usually is a result of greater concern with novelty the rational approach by contrast is more frequently a result of evolution from the traditions of architecture design.

The design process-systems framework is seen from the perspective of the general systems theory ${ }^{38}$ as the knowledge-based systems network is in constant interaction with the wider knowledge environment. The hypothesis of the study suggests that design knowledge develops through knowledge interaction involving receiving, producing and communicating knowledge back

35. Dorst, "The problem of design problems."

36. Cross, From a design science to a design discipline: Understanding designerly ways of knowing and thinking; Dorst, "The problem of design problems," 05.

37. Grout and Wang, Architectural Research Methods.

38. Von Bertalanffy, General system theory. 
to the environment. This mechanism should be the main concern in any 'theory of design knowledge'.

The 'theory of design knowledge' aims to explain the mechanism of knowledge development, through which knowledge is exchanged and communicated with the wider knowledge environment. It should explain the way the development of knowledge operates through the rational and the creative channels of design process-systems. It defines the strategies, through which the different types of knowledge develop including the design proposal, design theory and design concepts. To accomplish this task, analysis of empirical data from the studio is used in verifying the theory of design knowledge. The three strategies managing the development of design knowledge shall be discussed in the coming sections of the research project. But before the investigation of the knowledge mechanism and the role of rational and creative approaches in students work, it is necessary to learn how studies consider design problems and to identify the position the theory of design knowledge holds in that respect.

In the 1980s, many design methodologists claimed that the property of design problems is indeterminate. Nevertheless, they shared a common view that even though the property of design problems is indeterminate, the approach to indeterminate problems can be scientific. ${ }^{39}$ Dorst (2003) suggested that design problems have a threefold nature: they are partly determined, largely under-determined and somewhat undetermined. Determined knowledge is the type of knowledge, which can very well be described and modeled within the rational problem solving paradigm. The under-determined part is concerned with the interpretation of design problems and the creation and selection of possible suitable solutions, which can only be decided on the basis of proposals made by the designer. The third part is the undetermined knowledge, in the sense that the designer is to a large extent free to design according to his own taste, style and abilities. ${ }^{40}$

It is known that the rational problem solving paradigm is based upon positivistic epistemology. The integrated design paradigm, similar to the rational problem solving approach, considers design problems from a positivistic view point. They both consider design problems within an objective world that should be studied and responded to with scientific methods. Therefore, the integrated design paradigm considers the knowledge of design problem as seen from a positivistic view point, using the terms of Dorst, as determined or underdetermined.

To overcome the indetermination of design problems as a necessary step towards the integration of the rational and creative knowledge the theory of design knowledge tries to find a determinate area in the interpretive part of design knowledge. The determinate part of creative work, as the study suggests, is the one learned by the study of past experiences in design. The argument is trying to widen the part that is considered determinate by reducing

39. Cross, "Designerly ways of knowing: Design discipline versus design science"; Jones, Design Methods.

40. Dorst, "The problem of design problems." 
the part that is considered indeterminate. The indeterminate part can be reduced considerably depending on the position of the architect from the objective or subjective interpretation of the design problem.

\section{A Proposed Model of Design Process-Systems}

Architecture design research can be undertaken for different purposes and in different contexts. Three categories of design research are identified in the literature, they are: research for design, research through design and research about design. ${ }^{41}$ This study is concerned with the first two categories namely research for design, and research through design.

'Research for design' encompasses those activities or projects that aid and support design. Such projects may also involve designing but their main goal is to inform or support the design process. ${ }^{42}$ In his book Design Research, Downton calls this area "research to enable design". This research area provides the information, implications, and data that designers can apply to achieve an end-result in their design projects. ${ }^{43}$

'Research through design' involves disciplinary specific practices where design is itself utilized as a research practice, constituting both the means and outcome. ${ }^{44}$ In this approach, the emphasis is on the research objective of creating design knowledge, not the project solution. The most important aspect of research through design is that it seeks to provide an explanation or theory within a broader context. It may combine the practice-based research approach of practitioners with reflection on a research question that "is not restricted to the product on which research is being conducted". 45

Findeli, according to Frankel and Racine (2010), ${ }^{46}$ differentiates the two design research approaches by associating "through design" with theory and "for design" with practice. The master studio is interested in the type of research, which forms an integral component of the design process during defining the design problem and finding the problem solving approach and the study of the precedents. This type of research provides knowledge, which can be used repeatedly to inform a widened domain across the design process. Within this broad framework, the master students choose either 'research for design' or 'research through design' methodology according to what best serves their project objectives.

41. Lois Frankel and Martin Racine, The complex field of research: for design, through design, and about design (2010).

42. Robyn Barnacle, Mapping Design Research at RMIT (Research Training Group, RMIT Press, 2003).

43. Frankel and Racine, The complex field of research: for design, through design, and about design.

44. Barnacle, Mapping Design Research at RMIT.

45. Frankel and Racine, The complex field of research: for design, through design, and about design.

46. Ibid. 
Table 1. A Concise Model of Design Process-Systems

\begin{tabular}{|c|c|c|c|}
\hline \multirow[t]{2}{*}{$\mathrm{Nc}$} & \multirow[t]{2}{*}{ Process } & \multicolumn{2}{|l|}{ Activities } \\
\hline & & Producing knowledge & Using knowledge \\
\hline 1 & $\begin{array}{l}\text { Phase } \\
\text { (I) }\end{array}$ & $\begin{array}{l}\text { define design problem, } \\
\text { articulate problem-solving } \\
\text { approach; } \\
\text { - } \text { undertake background } \\
\text { preparatory research in the } \\
\text { literature; } \\
\text { - articulate design proposal, } \\
\text { design criteria; } \\
\text { - Identify research plan. }\end{array}$ & \\
\hline 2 & $\begin{array}{l}\text { Phase } \\
\text { (II) }\end{array}$ & $\begin{array}{l}\text { review the literature, } \\
\text { analyze, evaluate design } \\
\text { documents; } \\
\text { - formulate design theory; } \\
\text { - case-study; } \\
\text { refine theory of design } \\
\text { knowledge. }\end{array}$ & \\
\hline 3 & $\begin{array}{l}\text { Phase } \\
\text { (III) }\end{array}$ & & $\begin{array}{l}\text { - } \text { generate multiple } \\
\text { concept options, } \\
\text { select best concept } \\
\text { according to criteria; } \\
\text { refine design } \\
\text { proposal; } \\
\text { discussion and } \\
\text { results. }\end{array}$ \\
\hline
\end{tabular}

In this study, the term 'research project' is used to refer to the overall structure of the research study. In their book 'Architectural Design Methods', Grout and Wang (2002) ${ }^{47}$ defined a conceptual model of concentric frames to describe the structure of research activity. In the research project, following Grout and Wang (2002), ${ }^{48}$ the integrated design paradigm in the broadest frame is the system of inquiry, within which a specific model of the design processsystem operates as research methodology at the intermediate level. The model (Table 1) has been developed in the studio. It has double functions: it is developed as a research plan framed by the integrated design paradigm, where the proposed theory of design knowledge will be developed and tested; and at the same time is being used by students as a methodology of design research. Within the research plan there are three strategies concerned with the development of knowledge in the following order: defining the design problem and problem solving approach; formulating the design theory based on the study of the precedents, and; generating design concepts.

47. Grout and Wang, Architectural Research Methods.

48. Ibid. 


\section{Design Context and the Significance for Balanced Integration in Design}

Degree programs in architecture research usually offer multiple areas of specialization or emphasis. In the master program research is undertaken within a specific context deriving from a range of contemporary issues of local and global concern such as sustainability and smart-tech-integrated design. Several such issues were discussed in the studio of which two issues particularly captured the students' interest. The first is the question of sustainable architecture, with emphasis on the preservation of the natural resources. The second one is related to architecture design in the age of smart technology. The emphasis is on the integration of smart digital communication systems with space-layout in health-care facility design.

Lawson (2005) called such design interest, motivations. He showed that designers have their own motivations, reasons that direct their design and described that as sets of beliefs, values and attitudes. In the master studio, these ideals are not developed as a coherent philosophy and may not be developed yet as a complete theory of design, but can certainly be seen as a set of guiding principles as Lawson (2005) suggested. ${ }^{49}$

The newly discovered interest in design within specific contexts has encouraged a non-conventional discussion, innovative thinking and raised many questions. Interesting questions emerged such as how to build schools cheaper, quicker and with less impact on the environment; how can smart technology integrated design improve health care services. Students engaged in these avenues of research have shown a greater interest in design issues within specific contexts particularly in areas of national interest. One example showed a growing concern for preserving the natural environment and the beauty of the landscape, especially in an urban context. Another student is concerned with the impact of the official design in the new developed market places on the environment and cultural heritage. The student's motivation is the need for a design that is more sensitive to the traditional environment.

A third group of students takes interest in the issues related to the interaction between smart technology and architecture design in educational buildings and in health care facilities. Important questions raised are focused on the integration of modern digital communication technology on design, more precisely how architecture design can benefit from or increases the efficiency of the use of smart technology in buildings. Questions such as: To what extent can more informed choice of smart-technology applications by the design team contribute to better design quality? How can good architecture design support the efficient use of smart technology and improve the delivery of health care services?

It is noted from the discussion that the non-conventional interest in design within a specific context has led to change in focus away from the end product to the wider process. A significant result of the change is that the relationship between the design problem and the problem solving is now more clearly understood on basis of the complementary nature of their rational and the

49. Lawson, How designers think: The design process demystified. 
creative knowledge content. It has been suggested that central in modern design thinking is that design problems and problem solving are seen as emerging together, rather than one following upon the other. The reason as often mentioned in the literature is that design problems and problem solving are mutually interdependent in terms of the type of knowledge involved: the rational and the creative knowledge. The interdependent characteristic of the rational and the creative knowledge was described by Cross et al. (1981). They showed the interdependence of the rational and the creative knowledge in two ways. First, the rational approach is based on the 'knowing that' knowledge, whereas the creative approach relies on both the 'knowing that' and the 'knowing how' knowledge. Second, the 'knowing that' knowledge depends on the 'knowing how' knowledge. ${ }^{50}$

Understanding the relationship between the rational and the creative design approaches on basis of knowledge interdependence as Cross et al. (1981) suggested, ${ }^{51}$ makes it easier to understand the co-emergence of the design problems and problem solving on a similar basis. This understanding indicates beyond any reasonable doubt that the co-emergence of design problems and problem solving is dependent on the integration of their rational and creative knowledge content. This conceptualization opens the way for further exploration of the complementary relationships of these approaches and brings the study closer to the research question: How do the rational and the creative knowledge of design problems integrate? The answer, as the study suggests, is that a balanced integration of the rational and the creative knowledge can be achieved by learning from the past experiences of design.

Testing the validity of the research assumption requires that the role of each of the rational and the creative design methods throughout the design process should be analyzed. The last section of the present article is devoted to an empirical study based on the master students design research. The importance of the design-process model is that it informs both students design research and the research project at the same time. The interface between the research project and students' research work is the empirical investigation through the research plan, which takes data from students' research giving the study an additional viability through cross-testing of results.

\section{The Empirical Study}

Lawson (2005) provided a concise history of the development of research methodology in design since 1980s. He showed that most of what had been written by then was not based on empirical research. "Many early writers didn't describe a design process they had observed, but one they believed logically must take place". Later research in design methodology put the designer in a laboratory environment so as to observe the process under more

50. Nigel Cross, John Naughton and David Walker, Design method and scientific method 2, no. 4. IPC Business Press (1981).

51. Ibid. 
objective and rigorous empirical conditions. Lawson described several other developments in design research methodologies including the more recent simple technique of asking designers to tell the researcher what they do either by interviewing them or by reading what they have written about their process. $^{52}$

In his survey Lawson $(2005)^{53}$ discussed the different research methodologies identified the merits or the weaknesses of each one of them. In the empirical study conducted in the master studio, two methodologies mentioned in Lawson's list are used. Firstly, observing students at work in the studio who are themselves involved in doing research.

Secondly, analyzing students' own account of the process. They will be asked to reflect on their experience in the design research project by responding to a questionnaire. A questionnaire to survey students' attitudes in relation to the development of the design process-system will be presented to students after the task has ended. The questionnaire includes 14 questions, which request from the students to reflect on various aspects of the design process. The respondent students' feedback will be a useful to aid observation based analysis.

The discussion is focused on students' inquiry in the three principle strategies: defining design problem, articulating problem-solving approach and formulating design proposal; case-study research leading to the formulation of design theory, and; design concepts generation. In the present article the analysis of students' research work under the first strategy, namely defining the design problem, identifying problem solving and articulating the design proposal is presented. The research findings under the two other strategies will have to be dealt with in a future article when all necessary data becomes available.

\section{The Knowledge Development Mechanism}

The design process-systems framework is organized according to knowledge development mechanism into three strategies of knowledge produce and knowledge use. Strategies (I) and (II) are concerned with knowledge produce, strategy (III) is focused on knowledge use.

Strategy (I) is an inquiry that aims to define design problem and problem solving in terms of needs and the arrangement of space requirements. This inquiry involves research in two areas, conducted almost in parallel, concerning: (a) defining the design problem with emphasis on a specific predetermined design context. Different research methods were used, including interviewing all people concerned in addition to the use of questionnaires. Research was aided by background preparatory research; (b) identifying a problem solving approach. This latter enquiry involves design documents

52. Lawson, How designers think: The design process demystified.

53. Ibid. 
research has helped students to get acquainted with the design norms in the type of buildings they need to design.

Strategy (II): This is an inquiry in design precedents, which aims to act as a source of knowledge and as design examples. It involves two types of research methods: literature review to initiate design theory and case-study research to verify design theory.

The information acquired in the inquiry both in phase one and in phase two, through data collection and analysis can be described and modeled within the rational paradigm as determinate knowledge. It is important to note here that the determinate part of the design problem is enlarged considerably by adding the search for the problem solving model to the objective knowledge, which is learned by studying the precedents. This method can lead to reducing the gap in the design process-system between function and form considerably and gradually integrating the rational and the creative knowledge.

Strategy (III): The conventional design process usually relies on implicit methods and sketching in the development of design planning and three dimensional representations of forms. In the master class, it is noted that students take a distinctly different approach, which seems to emerge from the growing interest in the design process and changing nature of the design product. They began the process with a written statement, which describes several design concepts or ideas, the rationale that lead to such concepts and also the reasoning that supports decision-making in each case. The written statement is supported by sketching to illustrate each of the various proposals showing design planning and the creative embodiment of design proposal into a three dimensional context.

Design concept generation is based in most cases on a model drawn from the literature, but also on experimented designs, which have previously proved adequate. This practice has in most cases involved modifying the model to suite new technology and future needs. It is noted that the master student's sketching is different in that it takes the form of a diagrammatic illustration, which aims to demonstrate spatial relationships instead of the dominant artistic drawings in the conventional studio. The step ended with a selection of the best proposal according to the criteria.

Knowledge use is partly concerned with what studies describe as indeterminate knowledge. Dorst $(2003)^{54}$ claimed that the major part of the design problem is considered as underdetermined in which normally both the possible interpretation of the design problem and selection of possible suitable solution of the problem can only be made on the basis of proposals made by the designer. The study argues that the indetermination of this part of the design problem can, as already explained before, be considerably reduced by using the model from the study of the precedents.

To reduce the indetermination of the design problem, the theory of design knowledge proposes the use of objective interpretation as Dorst (2003) suggested. ${ }^{55}$ Dorst, based on Gadamer (1986), ${ }^{56}$ suggested that if objective

54. Dorst, "The problem of design problems."

55. Ibid. 
interpretation is applied to design we can see that the decision whether a part of a design activity will involve 'objective' or 'subjective' interpretation ultimately rests with the designer working on the design problem. ${ }^{57}$ In the case of the master class, students are engaged in design within specific contexts, which reflect areas of national interests or community development concern. In such a case there is a vested interest as students have shown in objectifying design goals and decision-making, leading to eliminating the tendency of subjective interpretation as Dorst suggested. Now the study can be reasonably justified when arguing that the design activities in which the objective interpretation plays a major role, such as the case supported by the integrated design paradigm, design problems may be viewed as largely determinate.

\section{Strategy (I): The Development of Design Proposal}

As soon as the design research area of interest established, the design research problem should be defined in a systematic manner. The technique normally involves a few steps such as, or similar to, the following: (i) Defining a well-focused problem; (ii) undertaking background preparatory research aiming at defining the design-problem-solving approach (iii) formulating the research topic and establishing a theoretical framework or context within which the study is conducted; (iv) identifying the research plan; (v) articulating the research problem into a design research proposal. In making a statement of the problem students in the research studio were engaged in the following:

Defining the design-research problem involves a preliminary investigation including interviews with the aim to identify need and values of the owner, the users and the society at large. The problem has initially to be stated in a broad general way, keeping in view either some practical concern, some scientific or intellectual interest as design context.

Undertaking background preparatory research in the literature is a process, as already explained in some detail earlier that helps focusing on the emerging research topic. It involves a systematic inquiry leading to defining the design problem and problem solving approach in terms of need and space requirements curried out almost in parallel as mentioned above. The investigation involves primary and secondary sources. The first is collecting data using various methods including interviewing the owner and other people concerned in additional questionnaires are also used. The secondary information is focused on design document research, which aims (a) to support the primary data concerned with defining the design problem (b) to articulate the problem solving approach.

Identifying the research plan has to state the conceptual structure within which research would be conducted. The research plan indicates the procedure, methodology and decides on the most appropriate methods for gathering data,

56. Hans-Georg Gadamer, The relevance of the beautiful and other essays (Cambridge: Cambridge University Press, 1986).

57. Dorst, "The problem of design problems." 
e.g. questionnaire; observation; review of available information; reflection on practice etc. in addition to the analysis and interpretation of data.

Articulating the design research proposal requires rephrasing the design research problem into analytical or operational terms i.e., to put the problem in as specific terms- framing- as possible. This enables establishing a theoretical framework within which the study is conducted and finally to formulate a design proposal.

The design research proposal is a conceptual formulation of the problem and problem solving scenario. The design proposal as developed in the studio, takes the form of a written document with illustrations of diagrams, which serves several purposes. The document represents a comprehensive programming research which has goals and ways to achieve goals. It suggests the area of research investigation, the scope of the literature review and formulates the research questions. The proposal reflects the basis upon which the design theory will be developed, and lays out the theoretical foundation for concept generation.

\section{Conclusions}

Studies showed that design is usually a result of integrated thinking. However, we don't seem to know how the rational and the creative knowledge within the design process actually integrate. Since the 1980s, many design methodologists claimed that the property of design problems is indeterminate. They showed that the indetermination of design problems make up a gap between the rational and creative knowledge. However, designers somehow overcome the indetermination of design problems and manage to bridge the gap between the rational and creative knowledge in the design processes. ${ }^{58}$ This trend obviously happens in an implicit way through practicing in the conventional design approach. The study claims that the integration of the rational and the creative knowledge can be captured and explained explicitly.

The study presents two methods to deal with this claim. The first suggests that the integration of the rational and the creative knowledge components of the design process-system can be objectively realized by learning from the design experience of the past. To overcome the indetermination of design problems and to integrate the rational and creative knowledge the theory of design knowledge proposes to find a determinate area in the creative knowledge component of the design process. The argument it presents is trying to widen the part that is considered determinate, by reducing the part that is considered indeterminate. Based on the empirical investigation in the studio, the determinate part of design problems has been enlarged considerably by adding the search for problem solving to the objective knowledge learned by studying the precedents.

The other method is focused on the type of knowledge involved in the creation activity referred to as Knowledge use, which is partly concerned with

58. Dorst, "The problem of design problems." 
the type of knowledge described as indeterminate. However, the study finds that indeterminate knowledge constitutes only a small part of what knowledge use activity relies on. It relies more on the rational knowledge learned from the study of the precedents as already mentioned. It is suggested that the indeterminate part can be reduced considerably depending on the architect's objective or subjective interpretation of the design problem. ${ }^{59}$ In the case of the master class where students showed interest in designing within a specific context particularly in areas of national concern, there is a vested emphasis to objectify the goals and to eliminate subjective interpretation as Dorst (2003) suggested. ${ }^{60}$

The study argues that the design activities in which objective interpretation plays a major role, such as the case supported by the integrated design paradigm, design problems may be viewed as largely determinate and only partly indeterminate. The initial investigation in the process indicates that the limited area of indeterminate knowledge or creative skill may be learned by doing, by watching others or by learning from the study of the precedents. Trying to capture the indeterminate knowledge by sensing in such a way, supports the research hypothesis that blending the rational and the creative knowledge can be explicitly realized through evolution by learning and adapting the experiences of the past to modern technology and future needs.

These two methods are initially presented by the study in his article to deal with the claim made earlier that the integration of the rational and the creative knowledge can be captured and explained explicitly. The study suggests these methods can lead to gradually integrating the rational and the creative knowledge and closing the gap in the design process-system between function and form. The two methods will be further investigated and empirically verified by comparison with case-study research in the remaining part of the research project.

59. Ibid.

60. Ibid. 


\section{Bibliography}

Bashier, Fathi. "Reflections on architecture design education: The return of rationalism in the studio." In Frontiers of Architectural Research. Elsevier (2014). DOI: 10.1016/j.foar.2014.08.004.

Bashier, Fathi. "Reflections on architecture design education (II): The integrated design paradigm." In International Journal of Science and Technology (STECH) 5, no. 1 (2016): 1-13. DOI: http://bit.ly/2hUmdR2.

Barnacle, Robyn. Mapping Design Research at RMIT. Research Training Group, RMIT Press, 2003.

Bayazit, Nigan. "Investigating design: a review of forty years of design research." Design Issues 20, no. 1. Massachusetts Institute of Technology (2004). Available at: http://www.ida.liu.se/steho/desres/bayazit.pdf.

Casakin, Hernan. Factors of design problem-solving and their contribution to creativity. 2008.

Coolican, Hugh. Research Methods and Statistics in Psychology. $4^{\text {th }}$ Edition. London: Hodder Arnold, 2004.

Cross, Nigel. "Designerly ways of knowing: Design discipline versus design science." Design Issues 17, no. 3 (2001): 49-55.

Cross, Nigel. From a design science to a design discipline: Understanding designerly ways of knowing and thinking. 2007. Available at: http://bit.ly/2hS QYDn.

Cross, Nigel. Design thinking. London: Bloomsbury Publishing Plc, 2011.

Cross, Nigel, John Naughton and David Walker. Design method and scientific method 2, no. 4. IPC Business Press (1981). Available at: http://bit.ly/2hbLWL.

Dorst, Kees. The Design Methodology Group. Faculty of Industrial Design Engineering. TU Delft, 1995. Available at: http://bit.ly/2hH9u3V. [Retrieved April 2014].

Dorst, Kees. "The problem of design problems." In Expertise in design, Design Thinking Research Symposium 6. Edited by E. Edmonds and N. G. Cross. Australia: Creativity and Cognition Studies Press, 2003, 17-19. Available at: http://bit.ly/2i9S2G8.

Frankel, Lois and Racine, Martin. The complex field of research: for design, through design, and about design. 2010. Available at: http://bit.ly/2hUg6fu.

Gadamer, Hans-Georg. The relevance of the beautiful and other essays. Cambridge: Cambridge University Press, 1986.

Grout, Linda and Wang, David. Architectural Research Methods. New York: John Wiley \& Sons. Inc., 2002.

Holm, Ivar. Ideas and Beliefs in Architecture and Industrial Design. Doctoral thesis. Oslo School of Architecture and Design, 2006.

Jaskiewicz, Tomasz. Process-driven architecture: Design techniques and methods. $3^{\text {rd }}$ Int"l IASCAAD Conference on embodying virtual architecture. Alexandria, Egypt: ASCAAD-07, 2007.

Jones, John Chris. Design Methods. $2^{\text {nd }}$ Edition. New York: John Wiley \& Sons Inc., 1992.

Kroes, Peter. Creativity and rationality in design: enemies or brothers in arms? CEPHAD 2010, Plenary session, the borderland between philosophy and design research. Copenhagen: DK- 2100 Copenhagen, 2010.

Lawson, Bryan. How designers think: The design process demystified. UK: Elsevier, 2005. 
Markus, Thomas A. "A doughnut model of the environment and its design.” In Design Participation. London: Academy Editions, 1972.

Owen, Charles. "Design research: building the knowledge base." In Design Studies 19, no. 1 (1998): 9-20. Available at: http://bit.ly/2h1h45e.

Owen, Charles. "Design thinking. What it is. Why it is different. Where it has new value." The International Conference on Design Research and Foundation for the Future October 18-November 1, 2005. USA: Institute of Design, Illinois Institute of Technology, 2005.

Owen, Charles. Design thinking: Driving innovation. USA: Institute of Design, Illinois Institute of Technology, 2006. Available at: www.id.iit.edu.

Schon, Donald A. The reflective practitioner: How professionals think in action. USA: Basic Books Inc., 1983.

Simon, Hurbert. The science of the artificial. Cambridge, MA: MIT Press, 1969.

Von Bertalanffy, Ludwig. General system theory. 1928. Available at: http://bit.ly/ 2dke8Ah.

Walonick, David S. General systems theory. 1993. Available at: http://bit.ly/2ieM t5n.

Wankat, Phillip C. and Frank S. Oreovicz. Teaching engineering. School of Chemical Engineering, Purdue University, 1993. Available at: http://enginee ring.purdue.edu. 
